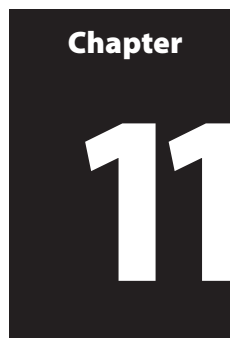

\title{
Mental Health Policy and Economics in Britain
}

\author{
Paul McCrone
}

\section{Introduction}

Economics and health care are fundamentally linked. Financial arguments have been influential in the development of mental health services over the ages, from the establishment of asylums through to their demise and replacement with other forms of care. This chapter presents some of the economic arguments that have been used around the process of moving from a predominantly hospital-based form of care in 1960 to one in which community services were developed and expanded by 2010 .

\section{UK Economy and Health Spending, 1960-2010}

The fifty-year period from 1960 to 2010 witnessed huge political and economic change in the UK. The post-war consensus whereby governments (Conservative and Labour) followed largely Keynesian economic policies (which were relatively interventionist) continued until the emergence of the Margaret Thatcher administration in 1979. 'Thatcherism' was characterised by a desire (whether achieved or not is debatable) to reduce the role of government and to promote the private sector. This was clearly relaxed to some extent during the Labour governments of 1997-2010, and the financial crisis towards the end of that period resulted in government once again accepting a heavily interventionist role in the economy.

The amount of funds that a society devotes to health care (whether through public or private spending) is fundamentally a decision made by society or individuals. According to the Organisation for Economic Co-operation and Development (OECD), ${ }^{1}$ in 1960 gross domestic product (GDP) in the UK was $£ 26.1$ billion and by 2010 was $£ 1.6$ trillion. Adjusting for inflation gives an increase of some 336 per cent over this period. In 1960/1, the amount of GDP accounted for by health spending was 3.1 per cent and this had increased to 7.5 per cent by $2009 / 10$. $^{2}$ This still leaves more than 90 per cent of GDP going on non-health activities and so there is room for increases albeit with proportional reductions elsewhere. Can this be achieved? Given that in other areas productivity gains can be achieved through technological advancements, products in these areas are prone to becoming cheaper in real terms. More labour-intensive sectors (health but also education) do not experience such productivity gains and so, as an economy develops, we should expect and even welcome a greater proportion of spending going on those areas. This is an argument put forward strongly by the influential American economist William Baumol. ${ }^{3}$ However, governments around the world have appeared concerned about the rising costs of health care and cost-containment measures have been endorsed.

Unfortunately, it is not feasible to estimate how much funding has been allocated specifically to mental health care over the years. Different government agencies have had 
responsibility for this area and data have not been recorded consistently. In recent years, we do have such information for planned NHS spending. In 2007, for example, planned mental health expenditure amounted to $£ 8.4$ billion which was 12.4 per cent of all NHS spending. ${ }^{4}$

\section{Economic Arguments around Deinstitutionalisation}

Since the emergence of the large asylums in the Victorian period, there was an increase in the number of people detained in psychiatric hospitals, with stays frequently being longterm. The peak number of psychiatric beds in England was in 1955 (around 150,000 beds), ${ }^{5}$ and this was followed by a gradual decline facilitated in part by the emergence of new antipsychotic medication such as chlorpromazine. However, the asylums remained and came in for substantial criticism. In 1961, Enoch Powell, who was a health minister in the ruling Conservative government, gave his famous 'Water Tower speech' which many consider to have paved the way for the ultimate demise of the asylums. In current times, the development of community services while still maintaining a huge stock of hospital beds might seem unfeasible (see also Chapters 1 and 2). However, it is clear from Powell's speech that the stated intention was not that finance would act as a barrier to developing alternative forms of care and indeed that around half of capital expenditure at the time was already taking place in the community rather than in hospitals. Importantly, whether there was professional acceptance of the need for this move is unclear.

Subsequent policy documents developed further the move to care outside of the longstay institutions and economic factors clearly influenced these arguments. The report entitled Hospital Services for the Mentally Ill, ${ }^{6}$ published in 1971, proposed integrating physical and mental health care within district general hospitals (interestingly, very different from what we have today). That report recognised the need for extra resources resulting from a desired high staff-to-patient ratio for care to be provided adequately. The realisation that community provision would require properly resourcing was shown in the 1975 report Better Services for the Mentally Ill (see also Chapter 10). ${ }^{7}$ As well as emphasising that the running costs of community services would be high, the report also emphasised the imperative to upgrade the existing hospital services. Moving forward to 1989, the government published an official response to a seminal report led by Roy Griffiths (see also Chapter 12). ${ }^{8}$ The Caring for People report set down the idea of a purchaser/provider split for health care, which has been revisited on a number of occasions up to the present day. It did not, though, ring-fence resources for community services (as had been called for) unless these were developed jointly between health and social care agencies. ${ }^{9}$

\section{Financing Community Services}

It is notable that, while many would have viewed the closure of asylums and the development of community services as a way of saving money, many in government and the policy world clearly were of the view that community services would not come cheaply. In her book After the Asylums, Elaine Murphy highlighted a number of financial issues relating to community care in the UK. ${ }^{10}$ She noted the problem, which still applies today, that different agencies have different responsibilities in terms of provision and commissioning and this can lead to clashing priorities. When the asylums were established this was accompanied with a transfer of financial responsibility from local parishes to county councils who managed the asylums. With the emergence of the welfare state later in the twentieth century, housing benefit became available and this led to funds being transferred to the Department 
of Social Security. Jones pointed out that, while Joint Finance to encourage the development of community services became available from 1976, this represented just 1 per cent of NHS funds and discouraged the transfer of other funds from health authorities to local authorities. This, coupled with the immense pressure that local authorities came under in the early 1980s to contain spending (through rate capping, for example), meant that local services were poorly developed. The closure of long-stay hospitals should have released funds but unless whole wards or hospitals could be closed this would not materialise. In addition, the downsizing of hospitals meant that the costs per patient per day became very high. Jones was clear that to counter some of these problems there would need to be an effective system of bridging finance put in place (such as a dowry mechanism).

\section{Rationale for Economic Evaluations}

Any development in the way in which mental health care is provided has potential impacts on resources. New services usually require start-up costs and running costs can be quite different from those they are replacing. Clearly, there is a limit on funds available for health and social care. Economics is concerned with this issue of scarcity (hence it being dubbed the 'dismal science' by Thomas Carlyle in the nineteenth century) and whenever scarce resources are used in one particular way then there is an opportunity cost in that other potential uses for them are foregone.

The idea that resources are inherently scarce is a strong one - although it is important to bear in mind the arguments put forward by William Baumol described in the section 'UK Economy and Health Spending, 1960-2010'. This, coupled with the high demands for health care due in part to an ageing population but also demand for new ways of working, means that decisions are always being made about how best to use the resources we have available to us. This can be at a very specific level (e.g. what is the best form of care for someone with schizophrenia?) or at 'higher' levels (e.g. should we spend more on care for people with mental health problems or those with cancer?; should we be spending more on health or education or defence?). Such decisions have always been made and always will be. The methods of economic evaluation have been developed and operationalised to try and make this process better informed.

In establishing whether new forms of mental health provision represent value for money we need to combine information on the costs of care with evidence on outcomes. Simply focusing on costs is rarely sufficient - unless of course we are simply intent on identifying the least-cost option. Costs are, though, key to an economic evaluation and it is imperative that they are measured appropriately. In doing so, we must recognise that they can be borne by different agencies: the health service, social care departments, housing agencies, criminal justice services, education providers, social security systems, business, families and friends, and users of services themselves. Altering the way in which care is provided might have widespread impacts and capturing these is important. If one were to only focus on direct intervention costs, then key information might be missed. For example, some medications can be particularly expensive but if they result in savings elsewhere then such costs might well be offset if they prevent lengthy inpatient hospital stays or return patients more quickly to productive work.

Costs ultimately have to be either combined with or viewed alongside outcomes for those affected by changes in service delivery. In mental health care, this is of course primarily the user themselves, but families and wider society can also be affected. What 
outcomes should be included? Given that there is unlikely to be just one impact that is of interest, it may be that a range of outcomes are relevant. Policymakers in England (not the whole of the UK) generally favour the use of quality-adjusted life years (QALYs), which are a generic measure enabling, in theory, comparisons to be made across diverse health areas. QALYs have been used to evaluate mental health services but many would consider them to be too reductionist.

One outcome that has frequently been used in mental health evaluations has been the use of inpatient care. This has its merits. It is easily recorded and avoiding admission may be desirable. However, it has important limitations. It comes with an underlying assumption that inpatient care is 'bad' but for some it may be entirely necessary and good-quality care may be optimised in an inpatient setting. Furthermore, it is not a true outcome measure but rather a process measure. As such, it is more properly considered to be a cost rather than an outcome. Finally, use of inpatient care is directly associated with the provision of inpatient beds in the area. Reducing provision inevitably leads to reduced use.

\section{Economics of Deinstitutionalisation}

In the UK, the largest and most influential evaluation of a hospital closure programme was the Team for the Assessment Psychiatric Services (TAPS) study led by Julian Leff (see also Chapter 30). ${ }^{11}$ This focused on the closure of the Friern and Claybury hospitals in North London in the 1980s and the health economic component was conducted by the Personal Social Services Research Unit (PSSRU) at the University of Kent, led by Martin Knapp and Jennifer Beecham. ${ }^{12}$ The TAPS study followed cohorts of patients as they were discharged from the hospitals over several years, usually to long-stay residential facilities. Not surprisingly, the patients who were considered easier to place in the community were discharged first and they had noticeably lower average weekly costs of community services than those discharged later. These costs include the residential facility plus other services used while in the community and any subsequent hospital care. The authors of the TAPS study also looked at the comparative costs (in 1993/4 $\mathfrak{k}$ ) of hospital- and community-based care. ${ }^{13}$ This showed that the average weekly cost when still in the Friern Hospital and Claybury Hospital was $£ 578$ and $£ 551$ respectively. This compares to $£ 539$ during the first year following discharge for cohorts $1-7$ and $£ 562$ in the fifth year following discharge for cohorts 1-3. What is clear from this is that the costs of community care were similar to hospital care and it was therefore not saving funds, even if that was desired by some.

\section{Inpatient and Residential Care since Deinstitutionalisation}

What can we say about inpatient care since the hospital closure programme has been largely completed? While the number of days spent in hospital for mental health reasons fell from when there was a peak number of 150,000 inpatients at any one time in 1955, in recent times the number of days has been fairly stable. Data from the Department of Health's Hospital Episode Statistics show that, in 1998/9, there were 7,029,445 days spent in hospital by people with a psychiatric diagnosis and, by $2009 / 10$, the figure was $7,482,979 .{ }^{14}$ This was also a time of comparatively high investment in community services and so probably indicates that this number of bed days (equivalent to around 20,000 beds) may be the minimum required.

Some patients do, though, remain as long-stay patients in hospital, and it is interesting to see what one year as an inpatient is equivalent to in terms of other forms of care. Box 11.1, where the numbers are based on unit costs produced by the University of Kent, shows that 


\section{Box 11.1 One Year in Hospital Is Equivalent to ...}

3,058 day care sessions

1,105 counselling sessions

1,095 staffed residential care days

577 outpatient appointments

969 psychologist contacts

2,803 community mental health nurse contacts

2,452 GP contacts

the amount of resources that could be provided is substantial. ${ }^{15}$ Of course, it may be unfeasible for some to be discharged from hospital, but these figures do illustrate the alternatives that are available. Even though residential care is expensive, it is far less so than inpatient care. It is also worth pointing out that one day in prison has a cost of around $£ 102$ which is substantially lower than hospital costs. ${ }^{16}$ It is well known that psychiatric morbidity in hospital is high, but the differences in costs between prisons and hospitals, especially secure units, can act as a disincentive to change location.

Inpatient stays remain a fundamental part of the care process within a mental health system and are also a highly expensive form of care. It is interesting therefore that there are relatively few studies that have investigated what actually takes place on inpatient wards and in particular there have been limited numbers of economic studies focusing on this. One major exception was the Patient Involvement in Improving the Evidence Base on Inpatient Care (PERCEIVE) study led by Til Wykes from King's College London and conducted in south London. This investigated care provided on seventeen inpatient wards and evaluated means of improving activities for patients. The economic analyses (described in depth by Sabes-Figuera and colleagues) ${ }^{17}$ were a novel departure from usual studies that have examined inpatient costs in that the focus was on activities and staff contacts that patients considered to be meaningful to them. Study participants were asked what meaningful care they had received in the previous week and, from this information, costs were calculated. Further analyses attempted to identify which patient characteristics were predictive of variations on the costs across the sample.

The patients reflected those found on many inpatient wards in inner-city areas in the UK. Schizophrenia or bipolar disorder was the diagnosis of 65 per cent, compulsory detentions were experienced also by 65 per cent, and 53 per cent were from a minority ethnic group. Therapeutic activities, including ward meetings, had been experienced by 78 per cent of the sample which was relatively encouraging. Meaningful staff contacts were reported by 90 per cent of patients (including 59 per cent with nurses, 74 per cent with psychiatrists and between 20 and 33 per cent with other professionals). While this might seem reasonable, it does mean that some patients were reporting no meaningful contacts at all. When it comes to costs of meaningful care, the average for the week was $£ 227$. Psychiatrist contacts made up 48 per cent of this, nurse contacts were 13 per cent and other therapeutic activities were also 13 per cent. This figure of $£ 227$ per week is substantially below the cost per day on a ward if the conventional approach to estimating unit costs 
is used. The implication is that, although staff may have different views, patients perceive much care they receive to not be meaningful or therapeutic.

The abovementioned TAPS study investigated discharge from long-stay hospitals and usually this was to supported accommodation in the community. The Quality and Effectiveness of Supported Tenancies (QuEST) study more than twenty years later, led by Helen Killaspy from University College London, evaluated care delivered in different forms of supported accommodation. ${ }^{18}$ A total of 619 residents were recruited for the study from residential care (which involved 24-hour staffing), supported housing (self-contained apartments with staffing up to 24 hours per day) and floating outreach arrangements (selfcontained tenancies with staff support). Various clinical measures were taken as well as quality of life, and service use was recorded and costs calculated.

The QuEST study revealed that quality of life was similar in residential care and supported housing but was lower in floating outreach arrangements. Satisfaction with care was similar under all three models. Service use in the previous three months showed relatively high levels of care coordinator, psychiatrist and other doctor contacts. Inpatient care was received by relatively few participants. Total care costs were similar between residential care and supported housing, while care costs for those in floating outreach arrangements were around one-third lower. This was not surprising given that those in these forms of care would presumably have lower levels of need.

\section{Economics of Specialist Services}

Shortly after the election of the Labour government in 1997, the Department of Health published the National Service Framework for Mental Health. ${ }^{19}$ This put forward the case for further developing specialist mental health services across the country. Three particular new models of teams and services were outlined: home treatment teams for people facing acute mental health crises; early intervention services for those with a first episode of psychosis; and assertive community treatment to improve contact with those who may be hard to engage with services. Though they had not been available across the whole country, such services had existed for many years in different settings. There was reasonably powerful evidence on the clinical benefits of the models but up-to-date evidence on their economic aspects was limited. A number of studies using similar methods were forthcoming though.

A randomised trial led by Sonia Johnson from University College London was conducted to compare a crisis intervention service with usual care in north London. ${ }^{20}$ The main outcome in this study was inpatient use over a six-month follow-up period and this was shown to be substantially less for those receiving the crisis service. The costs of the two forms of care were calculated and, given the main outcome, it was not surprising that crisis intervention resulted in large cost savings (around 30 per cent) compared to usual care. ${ }^{21}$

The Lambeth Early Onset study led by Tom Craig and Philippa Garety at King's College London was another trial, this time comparing early intervention for first-episode psychosis with usual care. ${ }^{22}$ The early intervention service resulted in reduced time in hospital. Costs for many services were higher for those receiving the service but total costs were lower due to the impact of reduced hospital time. ${ }^{23}$

The REACT study, led by Helen Killaspy, again at University College London, evaluated assertive community treatment in north London. ${ }^{24}$ The randomised trial took inpatient days over an eighteen-month period as the primary outcome measure and found no significant difference between assertive community treatment and usual care. The economic 
evaluation measured a range of services and calculated costs of these. The average cost over the eighteen-month period was $£ 34,572$ for assertive community treatment and $£ 30,541$ for usual care. Most of this cost was accounted for by inpatient care. ${ }^{25}$

These three studies have demonstrated that early intervention and crisis services certainly appear to represent some value for money. Less clear is the assertive community treatment. One potential reason for the lack of a significant effect for that service model was that usual care by the time of the study was well developed - certainly compared to the comparator groups in some of the early studies of assertive community treatment.

\section{Conclusion}

Economic considerations were a key influence in the development of mental health care in the period between 1960 and 2010. While some initiatives might have been seen as costsaving endeavours, it has been clear all along that good-quality mental health provision is not inexpensive. This, though, should not necessarily be seen as a problem - cost is only a monetary proxy for care provided and we would want care to be sufficient for those in need of it.

\section{Key Summary Points}

- Financial arguments have been influential in the development of mental health services over the ages, from the establishment of asylums through to their demise and replacement with other forms of care.

- In 1960, gross domestic product (GDP) in the UK was $£ 26.1$ billion and, by 2010 , was $£ 1.6$ trillion. Adjusting for inflation gives an increase of some 336 per cent over this time period. In 1960/1, the amount of GDP accounted for by health spending was 3.1 per cent and this had increased to 7.5 per cent by $2009 / 10$.

- Given that in other areas productivity gains can be achieved through technological advancements, products in these areas are prone to becoming cheaper in real terms. More labour-intensive sectors (health but also education) do not experience such productivity gains and so, as an economy develops, we should expect and even welcome a greater proportion of spending going on those areas.

- The TAPS study in north London in the 1980s showed that the average weekly cost when still in the Friern Hospital and Claybury Hospital was $£ 578$ and $£ 551$ respectively. This compares to $£ 539$ during the first year following discharge for cohorts $1-7$ and $£ 562$ in the fifth year following discharge for cohorts 1-3. What is clear from this is that the costs of community care were similar to hospital care and it was therefore not saving funds, even if that was desired by some. However, prison costs are lower than hospital costs and this may discourage admission of mentally ill patients to appropriate clinical facilities.

- Health economic studies carried out in London and published between 1999 and 2009 suggest that, while home treatment teams for people in acute mental health crises and early intervention teams may save money, assertive outreach teams for difficult-toengage patients may not. However, cost calculations do not address issues of quality of care and desired outcomes. 


\section{Notes}

1. See OECD.Stat, https://stats.oecd.org/\#.

2. R. Harker, NHS Funding and Expenditure. London: House of Commons Library, 2019.

3. W. J. Baumol, The Cost Disease. New Haven, CT: Yale University Press, 2012.

4. P. McCrone, S. Dhanasiri, A. Patel, M. Knapp and S. Lawton-Smith, Paying the Price: The Cost of Mental Health Care in England to 2026. London: King's Fund, 2008.

5. King's Fund, Mental Health Under Pressure. Briefing. www.kingsfund.org.uk/sites/default/files/field/field_ publication_file/mental-health-under-pressure-nov15_0.pdf

6. Department of health and Social Security, Hospital Services for the Mentally Ill. London: HMSO, 1971.

7. Department of health and Social Security, Better Services for the Mentally Ill. London: HMSO, 1975.

8. R. Griffiths, Community Care: Agenda for Action. A Report to the Secretary of State for Social Services. London: HMSO, 1988.

9. Department of Health, Caring for People: Community Care in the Next decade and Beyond, Cm 849. London: HMSO, 1989.

10. E. Murphy, After the Asylums: Community Care for People with Mental Illness. London: Faber \& Faber, 1991.

11. J. Leff, Care in the Community: Illusion or Reality? Chichester: John Wiley \& Sons, 1997.

12. J. Beecham, A. Hallam, M. Knapp et al., Costing care in hospital and in the community. In Leff, Care in the Community, 93-108.

13. A. Hallam, Affording community care: Lessons from the Friern and Claybury psychiatric reprovision programme. Mental Health Research Review (1995) 2: 29-32.

14. Department of Health, Hospital Episode Statistics.

15. L. Curtis, Unit Costs of Health and Social Care 2010. Canterbury: University of Kent, 2010.

16. Ministry of Justice, Costs per Place and Costs per Prisoner by Individual Prison. https://assets .publishing.service.gov.uk/government/uploads/system/uploads/attachment_data/file/218347/prison-costssummary-10-11.pdf

17. R. Sabes-Figuera, P. McCrone, E. Csipke et al., Predicting psychiatric inpatient costs. Social Psychiatry and Psychiatric Epidemiology (2016) 51: 303-8.

18. H. Killaspy, S. Priebe, S. Bremner et al., Quality of life, autonomy, satisfaction, and costs associated with mental health supported accommodation services in England: a national survey. Lancet Psychiatry (2016) 3:1129-37.

19. Department of Health, National Service Framework for Mental Health: Modern Standards and Service Models. London: Department of Health, 1999.

20. S. Johnson, F. Nolan, S. Pilling et al., Randomised controlled trial of acute mental health care by a crisis resolution team: The north Islington crisis study. British Medical Journal (2005) 331: 599.

21. P. McCrone, S. Johnson, F. Nolan et al., Economic evaluation of a crisis resolution service: A randomised controlled trial. Epidemiologia e Psichiatria Sociale (2009) 18: 54-8.

22. T. K. J. Craig, P. Garety, P. Power et al., The Lambeth Early Onset (LEO) Team: Randomised controlled trial of the effectiveness of specialised care for early psychosis. British Medical Journal (2004) 329: 1067.

23. P. McCrone, T. K. J. Craig, P. Power and P. A. Garety, Cost-effectiveness of an early intervention service for people with psychosis. British Journal of Psychiatry. (2010) 196(5): 377-82.

24. H. Killaspy, P. Bebbington, R. Blizard et al., The REACT study: Randomised evaluation of assertive community treatment in north London. British Medical Journal (2006) 32: 815-20.

25. P. McCrone, H. Killaspy, P. Bebbington et al., The REACT study: Cost-effectiveness analysis of assertive community treatment in north London. Psychiatric Services (2009) 60: 908-13. 